\title{
Updating of the Irish Food Composition Database for vitamin K1 and vitamin $\mathrm{K} 2$
}

\author{
C. Kingston ${ }^{1}$, L. Kehoe ${ }^{1}$, B.A. McNulty ${ }^{3}$, A.P. Nugent ${ }^{3,4}$, K.D. Cashman ${ }^{1}$, A. Flynn ${ }^{1}$ and \\ J. Walton ${ }^{1,2}$ \\ ${ }^{1}$ School of Food and Nutritional Sciences, University College Cork, Republic of Ireland, \\ ${ }^{2}$ Dept. Biological Sciences, Cork Institute of Technology, Republic of Ireland, \\ ${ }^{3} U C D$ Institute of Food and Health, University College Dublin, Belfield, Dublin 4, Republic of Ireland and \\ ${ }^{4}$ School of Biological Sciences, Institute for Global Food Security, Queens University Belfast, N. Ireland
}

There are limited data available on vitamin $\mathrm{K}$ intakes in national dietary surveys across Europe partly due to the lack of food composition data for vitamin K. The Irish Food Composition Database (IFCD) (2012) has been developed over the last 20 years informed by foods consumed on the Irish national dietary surveys (www.iuna.net). The IFCD (2012) has been updated for each survey to include brand level data and recipes of composite dishes. Each food and beverage consumed throughout the surveys was assigned a food code ( $n$ 3443), based on the food descriptor and the nutritional composition of the food. The aim of this study was to update the IFCD (2012) with composition values for vitamin $K_{1}$ and vitamin $K_{2}$ (menaquinone-4 (MK-4) and menaquinone-5 to 10 (MK-5-10)).

The vitamin $\mathrm{K}_{1}$ and vitamin $\mathrm{K}_{2}$ content of foods was determined using published analytical values from The UK Composition of Foods Integrated Datase ${ }^{(1)}$ (COFID), the United Stated Department of Agriculture (USDA) National Nutrient Database ${ }^{(2)}$, published papers, recipe calculation and manufacturers information. The table below outlines the proportion of vitamin $\mathrm{K}$ composition values assigned using each data source.

\begin{tabular}{|c|c|c|c|}
\hline Source of compostion data & Vitamin $\mathrm{K} 1$ & MK- $4 \%$ & $\overline{M K-5-10}$ \\
\hline Published analytical values & 52.5 & 13.6 & 14.6 \\
\hline UKCOFID nutrient databank ${ }^{l}$ & 30.7 & - & - \\
\hline USDA nutrient databank ${ }^{2}$ & 16.7 & - & - \\
\hline Published Papers & 5.1 & 13.6 & 14.6 \\
\hline Recipes & 30.4 & 27.3 & 27.1 \\
\hline Recipe calculated from ingredients list & 25.2 & 23.2 & 23.1 \\
\hline Similar to calculated recipes & 3.7 & 4.0 & 4.0 \\
\hline Retail Product calculated from ingredients list & 1.5 & - & - \\
\hline Manufacturers information & 10.5 & - & - \\
\hline Nutritional supplements & 9.9 & - & - \\
\hline Infant formula & 0.6 & - & - \\
\hline Foods that did not contain any vitamin $\mathrm{K}$ (as signed value of $0 \mu \mathrm{g}$ ) & 4.3 & 57.2 & 56.5 \\
\hline Other & 2.3 & 1.8 & 1.7 \\
\hline
\end{tabular}

Published analytical values for vitamin $\mathrm{K}_{1}$ provided composition data for $53 \%$ of food codes in the IFCD (2012). Each recipe in the IFCD (2012) was individually calculated for vitamin $\mathrm{K}$ content providing composition values for $29 \%$ of food codes for vitamin $\mathrm{K}_{1}$. The vitamin $\mathrm{K}_{1}$ composition values for $2 \%$ of food codes were calculated from the ingredients listed on packaging. Foods that did not contain any vitamin $\mathrm{K}_{1}(4 \%)$ were assigned a composition value of $0 \mu \mathrm{g} / 100 \mathrm{~g}$. Manufacturers' information provided vitamin $\mathrm{K}_{1}$ composition data for $11 \%$ of food codes. For MK-4 and MK-5-10, published analytical values provided composition data for 14 and $15 \%$ of food codes, respectively. Recipe calculation was used to estimate vitamin $\mathrm{K}_{2}$ composition values for $27 \%$ of food codes. Fifty-seven percent of food codes did not contain vitamin $\mathrm{K}_{2}$ and were assigned a composition value of $0 \mu \mathrm{g} / 100 \mathrm{~g}$.

These updates to the IFCD (2012) will allow for estimation of vitamin $\mathrm{K}_{1}$ and vitamin $\mathrm{K}_{2}$ intakes and sources in the Irish population and will add to the limited vitamin $\mathrm{K}$ composition data currently available in Ireland.

1. Public Health England (2015) PHE. London.

2. USDA National Nutrient Database for Standard References 28 (2015) https://ndb.nal.usda.gov/ndb/ 